University of Rhode Island

DigitalCommons@URI

\title{
Trust in China? The Impact of Development, Inequality, and Openness on Political Trust across China's Provinces, 2001-2012
}

\author{
Marc L. Hutchison \\ University of Rhode Island, mlhutch@uri.edu \\ Ping Xu \\ University of Rhode Island, pingxu@uri.edu
}

Follow this and additional works at: https://digitalcommons.uri.edu/psc_facpubs

\section{The University of Rhode Island Faculty have made this article openly available.}

Please let us know how Open Access to this research benefits you.

This is a pre-publication author manuscript of the final, published article.

Terms of Use

This article is made available under the terms and conditions applicable towards Open Access

Policy Articles, as set forth in our Terms of Use.

\section{Citation/Publisher Attribution}

Hutchison, Marc L., and Ping Xu. "Trust in China? The Impact of Development, Inequality, and Openness on Political Trust across China's Provinces, 2001-2012." Asian Journal of Comparative Politics, vol. 2, no. 2, June 2017, pp. 176-195, doi:10.1177/2057891116676409.

Available at: https://doi.org/10.1177/2057891116676409

This Article is brought to you for free and open access by the Political Science at DigitalCommons@URI. It has been accepted for inclusion in Political Science Faculty Publications by an authorized administrator of DigitalCommons@URI. For more information, please contact digitalcommons-group@uri.edu. 


\title{
Trust in China? \\ The Impact of Development, Inequality, and Openness on Political Trust across \\ China's Provinces, 2001-2012
}

\author{
Marc L. Hutchison \\ Associate Professor \\ Department of Political Science \\ University of Rhode Island \\ mlhutch@uri.edu \\ Ping Xu \\ Assistant Professor \\ Department of Political Science \\ University of Rhode Island \\ pingxu@uri.edu
}

\begin{abstract}
China has long represented a puzzle for scholars of democracy, who view political trust as an important indicator of regime legitimacy. Previous studies show that while democracies around the world experienced declining levels of political trust, the authoritarian Chinese government maintained unexpectedly high levels of trust. Using World Value Survey (WVS) data over a critical twelve-year period (2001-2012) and multilevel modeling techniques, we explore both macro- and individual-level determinants of political trust in China. We find that province-level economic performance and individual level income combine to influence political trust. Higher levels of individual-level income have a positive effect on trust in more developed provinces but the opposite effect in less developed provinces. Furthermore, individuals living in provinces with higher levels of inequality and openness tend to be less trusting of government. Our study offers critical insights not only for political trust in China but also the country's political future.
\end{abstract}

Keywords: China, political trust, economic development, income inequality, economic openness 
How has China's rapid economic growth influenced its citizens' overall trust in their governments? Over the last decade or so, several studies documented that China enjoyed unexpectedly high levels of political trust while many democracies experienced declining political trust (Wang 2005, 2007; Yang and Tang 2010; Chen and Shi 2001; Wong et al. 2011; Norris 2011; Li 2012). The World Values Surveys (WVS) reveal that political trust in China was not only significantly higher than in democracies but also remained relatively stable over time, as shown in Figure 1.

Figure 1. Aggregate Political Trust in China across Time

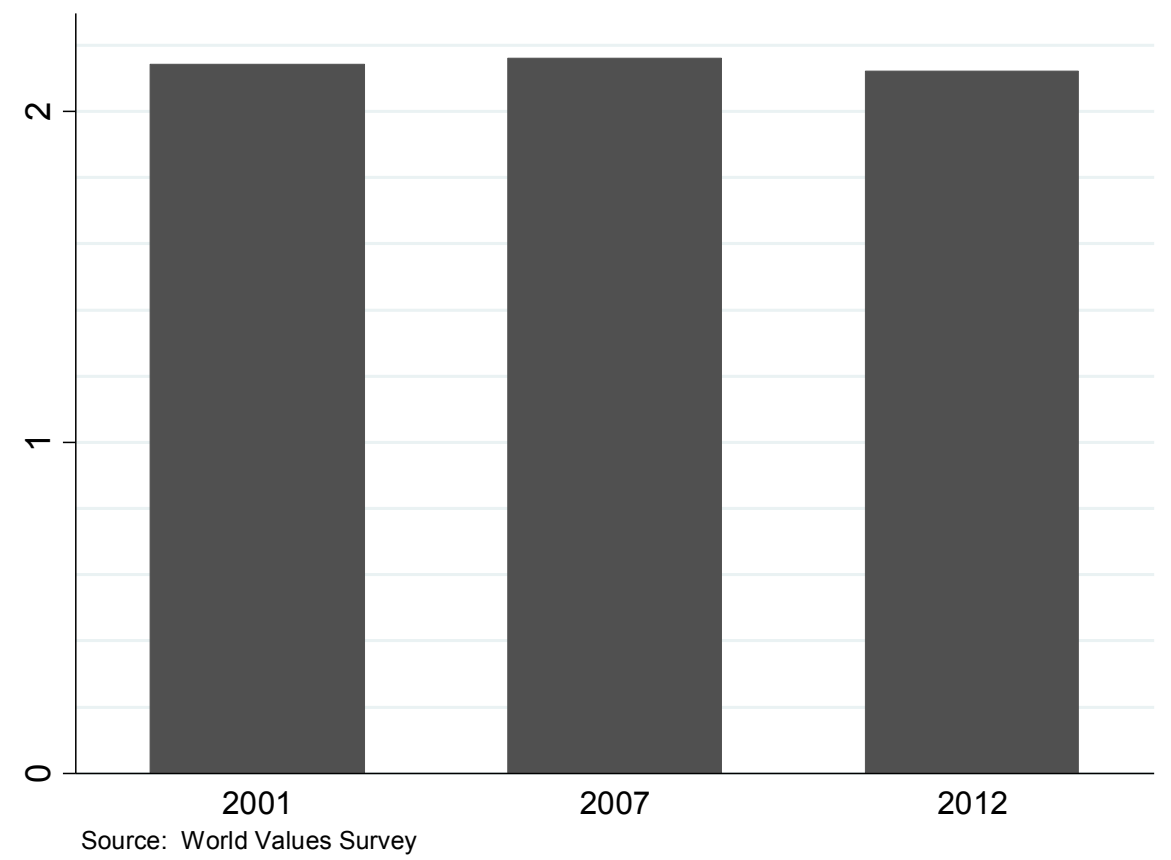

Note: The chart depicts the grand mean of political trust in China over time. Political trust measures individuals' mean confidence level in the following political institutions: the legislature, the central government, the army, the police and the civil services.

Given that trust in government, or political trust, is considered a critical indicator of regime legitimacy and often linked to democratic governance (Newton 2007; Zmerli and Van der Meer 2016), the roots of China's high political trust levels continue to puzzle scholars. Despite suspicion over the trustworthiness of the survey results and speculation that respondents might feel pressured 
to report higher levels of political trust in an authoritarian country, little evidence from previous studies shows support for these misgivings (see Newton 2001; Shi 2001). ${ }^{1}$ In the curious case of China, answers have often focused on Chinese government's remarkable economic performance as well as the role of a government-controlled media and education system (Li 2012; Wang 2007; Chen et al. 1997; Yang and Tang 2010; Wong et al. 2011; Kennedy 2009). Prior studies have primarily concentrated on using individual characteristics to explain political trust at the national level in China. Although China has witnessed tremendous changes in various aspects of its economic, social and political landscapes since the 1980s, few studies have examined the influence of these structural changes on citizens' attitudinal changes. In addition, most studies only consider a simple linear relationship between income and political trust and overlook potentially more complex relationships between individual income, macro-level economic performance and trust.

In this study, we argue that China's robust economic growth could indeed boost Chinese citizens' trust in their government but the relationship might be more nuanced than previously suggested. We assert that the various negative consequences associated with development, such as rising income inequality and regional imbalance in development, could erode Chinese citizens' support for their government (Li 2012; Wedeman 2005; Gustafsson et al. 2008). In addition, increasing openness likely brought liberal political thoughts pertinent to political freedom, human rights and democracy to Chinese citizens, possibly resulting in shifts in their political attitudes. To date, no one has systematically examined how these structural changes in China has influenced its citizens' political attitudes while accounting for regional differences. To fill in this gap, we collect data on these contextual variables at the provincial level, merge them with the individual-level public opinion data for a critical time period from 2001 to 2012 and examine their influence on individual political trust. 
Our results reveal that rural-urban income inequality and economic openness both erode trust in government and the relationship between provincial-level economic development and political trust is conditional upon one's individual income. Out of the three macro-level economic indicators, we find that per capita income and openness have large effects but rural-urban inequality also has a sizable influence on political trust. Our results suggest that Chinese citizens maintain a high level of political trust because the negative effects of inequality and openness have been largely offset by the strong positive effect of economic growth. However, no economy can expect to grow indefinitely. Economic slow-down, particularly an economic crisis, will likely result in a sharp decline in Chinese political trust as government performance fails to match citizen expectations. ${ }^{2}$ Given that openness remains the second strongest predictor of political trust and China has become increasingly open over time, Chinese citizens will be increasingly exposed to alternative political thoughts and ideologies that will, consequently, alter Chinese citizens' expectations of their governmental institutions and possible decrease their trust in government. Therefore, in order to maintain domestic political stability, the Chinese government must begin to tackle the inequality issue and adopt deeper political reforms. If left unaddressed, these two issues themselves may serve as the basis for a series of challenges from their own citizens regarding the governing legitimacy of the current regime.

In the sections that follow, we first introduce a multilevel theoretical framework. We propose some prominent province-level determinants of political trust in China, namely economic development, inequality, and openness. Based on these theoretical propositions we derive several hypotheses. In the following sections, we introduce our data and methods used to test the hypotheses and present the major findings. Finally, we conclude with a discussion of the results and their policy implications for China's political future. 


\section{The Multilevel Determinants of Political Trust}

Trust is an important element of political and social life in a society (Uslaner 2002). Often described as an enduring value because of its stability over time (see Knack and Keefer 1997), political trust is important to state functioning and is often considered an important attitudinal indicator of regime legitimacy (Mishler and Rose 2001; Hetherington 2005; Hutchison and Johnson 2011; Johnson and Hutchison 2012; also see Warren 1999). ${ }^{3}$

Despite its importance to regime legitimacy, cross-national studies of political trust have observed a troubling but consistent pattern of declining political trust levels across advanced industrial societies (Inglehart 1997; Dalton 2004; Inglehart and Welzel 2005; Norris 2011). Although cultural shifts (Inglehart 1997; Inglehart and Welzel 2005) and changes in media (Norris 2000) are among the most notable reasons proposed by previous research, Dalton (2004) contends that the trend is also likely due to changing citizen expectations and more diverse policy demands on government. In many developing countries where citizen expectations and policy demands are lower, overall political trust levels remain significantly higher compared to their more advanced counterparts, including China (see Norris 2011). These general global patterns in political trust over time suggest that China's rapid economic development may increase citizen expectations and jeopardize the current high levels of political trust over the long run.

Typically conceptualized as an individual's confidence in their government institutions, political trust is based in part on personal characteristics and dispositions in conjunction with their assessment of institutional performance (Norris 1999, 2011; Dalton 2004; Hetherington 2005; Newton 2007). Although political trust tends to be more enduring within countries over time, it varies considerably across countries leading Newton (2007: 205) to state that political trust is "a reflection of the external or objective conditions" rather than simply reflecting an individual disposition (also see Knack and Keefer 1997; Newton 2001; Uslaner 2002). Thus, the primary 
antecedents of individual political trust tend to be multilevel, shaped by both individual characteristics and contextual macro-level factors (Zmerli and Newton 2008; Newton and Zmerli 2011; Hutchison and Johnson 2011). Similarly, within countries, political trust can also vary considerably across regions with the variation largely attributable to differences in contextual factors rather than differences in individuals (Johnson and Hutchison 2012).

The causal mechanisms for political trust are complex. In previous research exploring the micro-foundations of political trust, one of the primary questions examined is whether political trust is a feature of the individual or a feature of the object. Increasingly, scholars have concluded that the answer is both. At its core, political trust is a relationship between the subject (the individual) and the object (political institution) shaped, in part, by the subject's disposition toward trust in general and their assessment of the object's performance (see Zmerli and Van der Meer 2016). The interplay between these two elements primarily shapes individual trust in political institutions. As we discuss below, in this study, we largely focus on controlling for individuals' trust disposition using common individual-level predictors of political trust and evaluate macro-level indicators of regional institutional performance shaping the assessment component of political trust decisions within China. At the province-level, we identify three important economic indicators relating to institutional performance-economic development, economic inequality, and openness.

\section{Individual-level Determinants of Political Trust}

The first component of political trust, the subject's disposition toward trust, is commonly viewed an underlying orientation shaped by certain personality traits. Prior studies suggest that cultural values and norms play an important role in shaping individual political trust (Almond and Verba 1963; Inglehart 1997; Inglehart and Welzel 2005; Shi 2001; Welzel et al. 2003; Dalton and Ong 2006; Yang and Tang 2010; Welzel 2011; Shin 2012). Considering the strong influence of Confucianism and communitarianism in China, we expect to find individual dispositions tapping 
into these unique Chinese cultures, such as one's tendency to respect the authority and generalized trust, have a stronger influence on political trust in China than in other countries (Shin 2012). ${ }^{4}$

We anticipate the effect of other individual characteristics to largely conform to the patterns found in other countries and regions, particularly those characteristics not directly linked to regime type or culture. For instance, we anticipate that socioeconomic factors and politically neutral attitudes and dispositions, such as economic satisfaction and national pride, will perform similarly in the Chinese context. We have included detailed explanations of these individual characteristics in the online appendix.

\section{Province-level Determinants of Political Trust}

A critically important component of political trust - an individual's assessment of the object's performance - is essentially an individual's evaluation of political institutions based, in part, on how well performance matches expectations (Jennings 1998; Dalton 2004; Norris 2011). This assessment process is heavily influenced by objective indicators of governmental performance (i.e. macro-level conditions). Typically, governments with higher performance are more trusted in comparative studies as individuals tend to trust governments that provide adequate services, are generally fair and competent, and maintain economic prosperity (Rothstein 2011; Uslaner 2011).

\section{Economic Performance}

The link between economic performance and political trust has been studied extensively, particularly in North America and Europe, with much of previous literature linking better economic performance results to higher political trust levels. Indeed, researchers examining political trust in China have documented economic performance as the single most important predictor of political trust in China (Chen et al. 1997; Wang 2005; Yang and Tang 2010; Wong et al. 2011). China's economy has grown immensely since the "open-up reform." With an average growth rate of 10\% for the past three decades, China has not had a major economic downturn yet (as shown in the chart 
of Figure 2). Yet, the reform featured early policies that opened up "special economic zones" on the east coast with tax exemption and subsidies to attract foreign investment, resulting in rapid economic development in the east coast and the West inland relatively poor and undeveloped. ${ }^{5}$

Figure 2. Economic Development in China

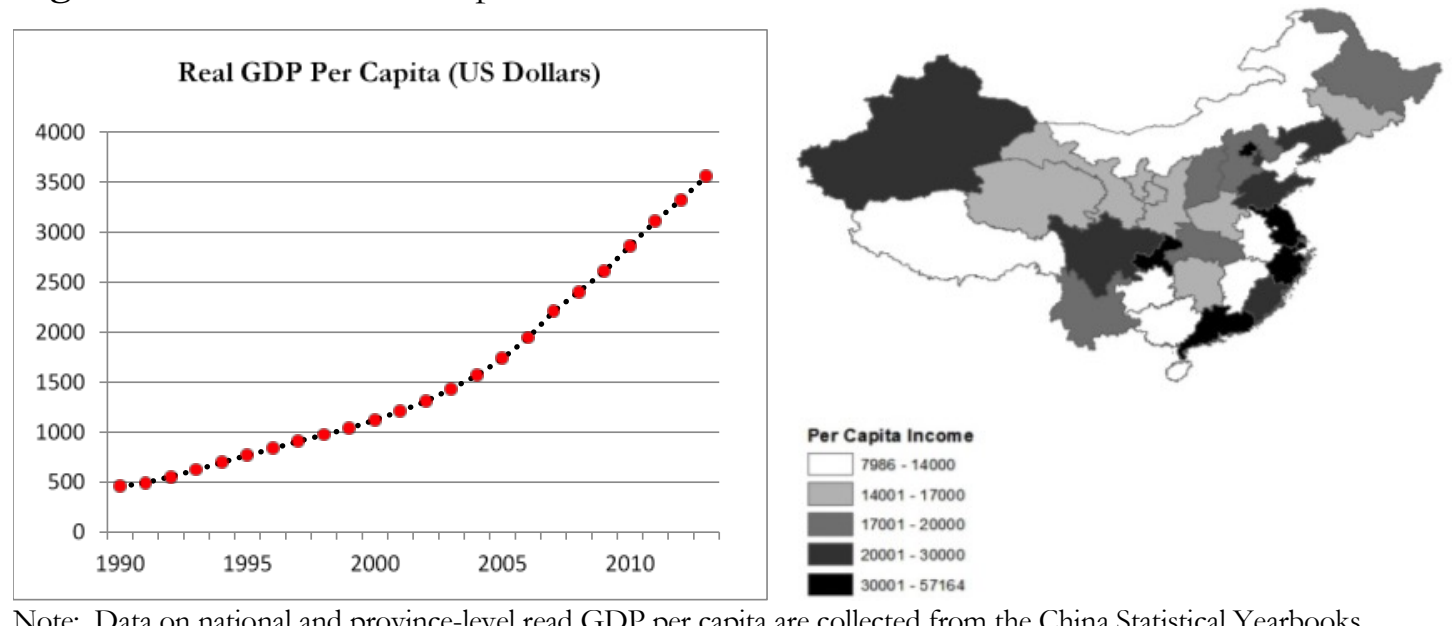

Note: Data on national and province-level read GDP per capita are collected from the China Statistical Yearbooks.

The map in Figure 2 demonstrates the imbalance of economic development across Chinese provinces. Considering the strong connection between economic development and political trust and the large regional variation in economic development levels, we expect individuals residing in more prosperous provinces to have a higher level of political trust.

\section{$\mathbf{H}_{1 \mathrm{a}}$ : Individuals in provinces with a higher average income will be more trusting government than individuals in provinces with a lower average income.}

Unlike previous literature suggesting a linear relationship between economic performance and political trust, we contend that individual income levels may moderate the effect of provincelevel economic performance on political trust in China. Indeed, previous studies reveal a more complex relationship between individual-level wealth and trust (Catterberg and Moreno 2005). In their study on the Dominican Republic, Espinal et al. (2006) find that the poorest and wealthiest individuals exhibited the highest levels of political trust, suggesting that the relationship between 
income and trust is not linear. Given that political trust has a strong evaluative component, province-level wealth may shape the expectations of economic performance of individuals residing in that region. While we still anticipate stark differences in overall trust levels between relatively wealthy and relatively poor provinces, we expect to find variation in trust levels across income groups between relatively wealthy and relatively poor provinces. We argue that wealthier individuals may have higher expectations of economic performance in their home province. Thus, wealthier individuals should be more trusting in wealthier provinces where the economic performance has matched their expectations (see Catterberg and Moreno 2005). However, in relatively poor districts, we contend that they may exhibit lower trust compared to poor residents given this disconnect between expectations and province economic performance. Based on this conditional effect, we develop a second hypothesis:

$\mathbf{H}_{1 \mathrm{~b}}$ : The effect of province-level wealth on political trust will vary across individual income groups.

\section{Economic Inequality}

Since the 1980s, China has experienced one of the largest increases in inequality in the world (Yang 1999), mainly manifested as enlarging rural-urban disparities (Kanbur and Zhang 1999). The Chinese government gave priority to the development of industry over agriculture in the early stages of the open-up reform. Heavy taxation and administrative fees were levied from agriculture to subsidize industry in urban areas (Kim 2010). Such policies directly led to the impoverishment of peasants in rural China. A German ambassador stationed in China once vividly commented on the polarization between the "thriving cities" and "impoverished countryside" in China by saying that "the urban area looks like Europe and rural area looks like Africa in China” (Xue 2013: 4).

The household registration (Hukou, or 户口 in Chinese) system further deteriorated the ruralurban disparity by segregating rural and urban residents. Impoverished peasants in China were locked in rural areas because "rural residents not registered in the cities could not enjoy urban 
lifestyles, housing, education, employment, welfare, retirement pension, etc.” (Xue 2013: 4). The chart in Figure 3 shows that the income ratio between the average urban and rural residents increased drastically from 1996 to 2003 and then stayed relatively stable and decreased somewhat after 2008. ${ }^{6}$ The map shows regional variation in urban-rural inequality across Chinese provinces.

Figure 3. Economic Inequality in China

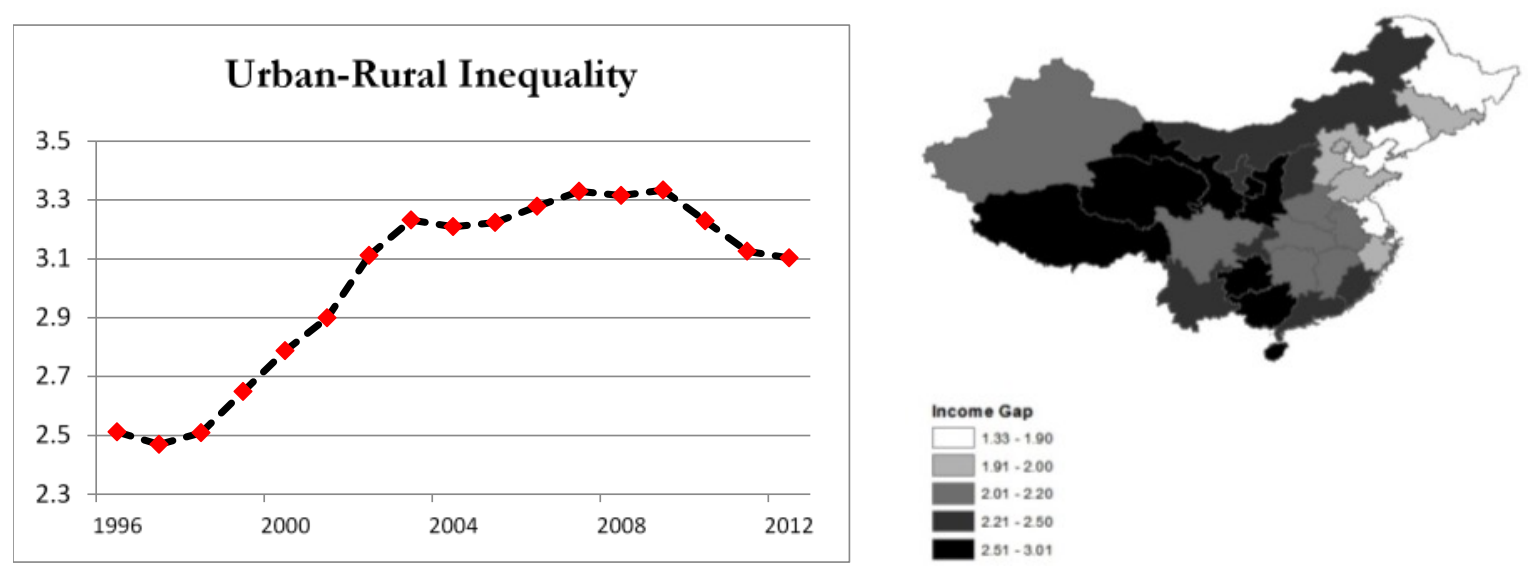

Note: Data on national and province-level urban-rural inequality are collected from the China Statistical Yearbooks.

We expect rising inequality to have negative effects on individual political trust, because sharp income inequality can be perceived as a policy failure. From a psychological standpoint, rising economic inequality could cause the feeling of relative deprivation, i.e., a discrepancy between what individuals anticipate receiving and what they actually get, resulting in frustration, anger, and dissatisfaction against the regime (Gurr 1970). When a handful Chinese cities and a small proportion of the population became much better off than the rest of the country, the majority of the population might feel relatively deprived and less trusting their government. The negative relationship between inequality and political trust has been consistently observed in cross-national studies (see Anderson and Singer 2008; Kumlin 2011). Based on this proposition, we develop the following hypothesis. 


\section{$\mathbf{H}_{2}$ : Individuals in provinces with higher urban-rural inequality will be less trusting of government than individuals in provinces with low levels of inequality.}

Openness

Higher levels of openness could erode political trust by increasing citizens' expectations for institutional performance. Since the open-up reform China has become increasingly accessible to the rest of the world. Openness has introduced liberal political thoughts pertinent to freedom of speech and association, human rights, government transparency, and democracy to China, resulting in waves of requests for political liberation by the Chinese people. ${ }^{7}$ Surprisingly, few studies have examined the effect of openness on individuals' attitudinal changes in China. We consider the varying degrees of openness across Chinese provinces and study its effect on political trust. As shown in Figure 4, we observe that China has been increasingly open to foreign countries, but the degree of economic openness varies across Chinese regions. ${ }^{8}$

Figure 4. Openness in China
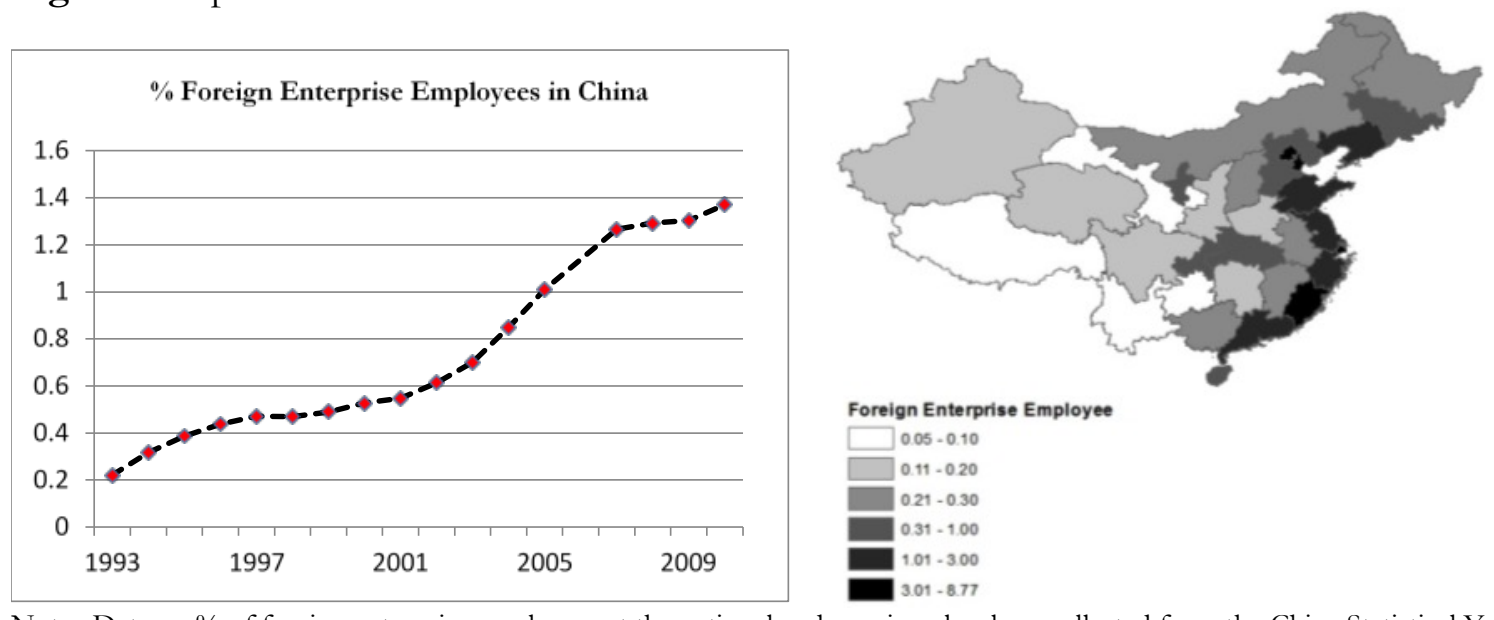

Note: Data on \% of foreign enterprise employees at the national and province-level are collected from the China Statistical Yearbook.

While the Chinese government tries to cultivate a positive self-image among its citizens through censorship and propaganda, individuals living in provinces with higher levels of openness will be more likely exposed to alternative information sources. In particular, we expect that exposure 
to alternative information sources pertaining democracy, government transparency, human rights and freedom of speech will result in individuals holding higher expectations for their governments in these areas. Therefore, we expect individuals residing in provinces with greater openness more likely to critically assess their governmental institutions and, subsequently, less trusting of their government than those residing in more closed provinces.

$\mathbf{H}_{3}$ : Individuals in provinces with high levels of openness will be less trusting of government than individuals in provinces with low levels of economic openness.

\section{Data, Variables, AND Method}

To test our hypotheses, we use a unique dataset combining province-level data collected in China and World Values Survey (WVS) data disaggregated across provinces and time. ${ }^{9}$ The WVS is one of the few cross-national surveys that measures political trust levels in a consistent manner over the span of decades allowing us to examine trends over time. With multiple surveys conducted in a wide range of Chinese provinces, the WVS also allows us to examine trust at the regional level. That said, the China surveys in the WVS do suffer from both sampling inconsistencies and incomplete geographic coverage of the entire country. ${ }^{10}$ In particular, the sampling framework for the 2001 WVS survey was more urban-biased than the 2007 and 2012 waves, which used more representative sampling strategies. ${ }^{11}$ To ensure that these changes in sampling procedures do not significantly change the results presented below, we re-estimated our models without the 2001 survey as a robustness check. These results are presented in Table A1 of the online appendix, and the substantive findings reported here remain unchanged.

\section{Dependent Variable}

Our primary dependent variable is an index of political trust comprised of multiple indicators on a broad range of institutions intended to provide a generalized measure of trust in government (also see Norris 2011). More specifically, we construct our measure by using the 
individuals' mean assessment of the following political institutions: the legislature (National People's Congress), the army, the central government, the police, and the civil services. For each indicator, respondents report their degree of confidence or trust along a four-point scale that ranges from 0 (no trust) to 3 (high trust).

It is worth noting that previous cross-national studies suggest that there may be two different dimensions of political trust: policy/decision-making institutions and security/social order institutions (see Inglehart 1997; Norris 2011). However, Norris (2011) finds this distinction only holds for older liberal democracies and this dimensionality was not evident for the rest of the world. Therefore, we emulate Norris' (2011) measure focused on capturing a broad assessment across several dimensions of government because we are trying to evaluate individuals' political trust in general and not just one particular sector or institution (also see Hutchison 2011; Hutchison and Johnson 2011; Zmerli and Van der Meer 2016).

The principle component factor analysis for our item index also does not indicate that the Chinese respondents differentiated the security and decision-making institutions along different dimensions. The Cronbach's Alpha score for the simple additive index of these indicators is 0.82 . Factor analysis revealed that all of the variables had an average loading of 0.67 . Furthermore, a factor score generated from this loading correlated with our measure at $99 \%$. While we are confident that aggregating our indicators into a broad measure of political trust, we re-estimated our models substituting a three-item index that excluded trust in armed forces and police for our dependent variable as a robustness check. These results are presented in Table A2 and Figure A1 of the online appendix, and the substantive findings reported here remain unchanged.

\section{Province-level Independent Variables}

Average Income. We include the province-level real per capita income as a macro-level variable for economic development in the province. We expect province-level development has a 
positive effect on individual trust in government, and that this relationship is conditional upon individual income. Data on real per capita income at the provincial level are collected from the Chinese Statistics Yearbooks.

Economic Inequality. We include the ratio of real per capita income in urban and rural areas as a measure of economic inequality. We expect that a higher level of urban-rural disparity in the province will lower its citizens' political trust. Data on rural and urban per capita incomes are collected from the China Statistics Bureau.

Openness. We argue that Chinese nationals living in more open provinces tend to be more critical of their government. We include \% of employees working in foreign enterprises out of all employees in the province as a measure of openness. We expect this variable to have a negative effect on political trust. Data on this measure are collected from the Chinese Statistical Yearbooks. ${ }^{12}$

We have also included two macro-level control variables-education rate and media density. There has been a wide range of research linking individual media exposure to lower political trust in democracies (e.g. Norris 2000; Hutchison 2011; Hutchison and Johnson 2011). Chen and Shi (2001) find that the news media in China have negative effects on people's attitudes toward political institutions in general and make people distrust government. They suggest that the saturation of official propaganda makes people think more about the messages and compare them with the political reality, and further discredit the information source (Chen and Shi 2001). Additionally, news media now not only cater to political dictates but also "the wants and needs of increasingly diversified and sophisticated audiences. Formerly forbidden areas such as societal news, human interest news, and critical reports have frequently been explored" (Chen and Shi 2001: 92). Citizens exposed to a more open and free media are more likely to evaluate the political reality and also be more critical of government. Following their insight, we include the number of newspaper and 
magazine subscriptions per 10,000 persons in each province as an indicator of media exposure. We choose newspapers and magazines because they are a highly censored media type in China.

Given that education plays an important role in political trust, we examine how provincelevel education levels influence individual trust in government in addition to one's individual-level education level. We argue that the overall regional education level could also influence trust in government through socialization. If an individual socializes with mostly highly educated individuals, he or she might be more critical of the governments. Given that higher educated citizens tend to be less trusting of government, we expect that higher levels of province-level education should have a negative influence on individual political trust. We include the percentage of provincial population that only completed the nine-year compulsory education but without any further education as a measure of overall education rate. Data on both macro-level controls are collected from the Chinese Statistical Yearbook.

\section{Individual-level Variables ${ }^{13}$}

We account for important individual-level predictors of political trust in the analyses in order to avoid serious omitted variable bias, and we use relatively standard individual-level model of trust similar to previous research in non-North American or European contexts (Hutchison 2011; Hutchison and Johnson 2011). However, due to space considerations, detailed descriptions of the individual-level control variables can be found in the online appendix.

\section{Statistical Method}

Since our explanatory variables involve both individual- and province-level factors and we employ survey data over a course of 12 years, our data present several methodological challenges. In this case, individuals are nested within surveys conducted throughout different Chinese provinces (spatial) at different points in time (temporal). To determine if multilevel modeling techniques are 
necessary, we first estimate a one-way Analysis of Variance (ANOVA) with survey year and region random effects to assess the degree to which variation in political trust is due to variation across individuals within regions and time versus variation between regions and time. In Table 1, the intraclass correlation indicates that $6.8 \%$ of the variation in political trust is due to variation across regions and time, which is to be expected, since we have hundreds of individuals across 19 regions over three points in time. Since the intraclass correlation here is not 0 , evaluating the effect of environmental conditions on individual-level behavior by using spatial differentiation (i.e., countries, regions and states) and temporal differentiation (Snijders and Bosker 2012) is appropriate. ${ }^{14}$ In the models below, we also report additional intraclass correlations to show how much unexplained variation between surveys is accounted for when we introduce our individual-level predictors and a full macro-micro-level random intercept model.

\section{RESULTS}

In Table 1, we present three multilevel political trust models using our political trust index. Model 1 offers the individual-level model to serve as a baseline for evaluation of the province-level factors affecting political trust. In Model 2, we incorporate our independent variables along with our two province-level control variables, education rate and media density, to the baseline model to jointly evaluate their independent effects in a full additive model.

We begin with the baseline model, Model 1, in which we estimate the effects of key individual-level predictors on political trust. In general, all the individual-level variables except individual income achieve statistical significance and influence political trust as expected. In particular, we find that individuals who exhibit higher levels of economic satisfaction, political salience, and national pride are more trusting of government, while the highly educated tend to be less trusting their government (also see Dalton 2004; Shin 2012). Given that we expect a conditional 
effect between individual income and province-level wealth, the parameter estimate for income is not surprising. As expected, individuals with higher tendency to respect the authority and generalized trust are more trusting the government. Additionally, the ICC coefficient indicates the Model 1 offers a noticeable improvement in accounting for unexplained variance across the surveys. ${ }^{15}$ In short, nothing in Models 1 indicates that individuals in China are qualitatively different from those in other countries or regions with respect to their individual-level antecedents of political trust.

In Model 2, we introduce our province-level variables on economic development, inequality, and openness in order to assess their effects on political trust. Consistent with our hypotheses $\left(\mathrm{H}_{1} \mathrm{a}\right.$ and $\mathrm{H}_{2}$ ), our results show that Chinese citizens in wealthier provinces have higher levels of overall political trust while those residing provinces with greater economic inequality are less trusting of government. ${ }^{16}$ We also find support for our contention $\left(\mathrm{H}_{3}\right)$ that greater openness negatively affects political trust. Finally, the ICC correlation for Model $2(.047)$ indicates a significant improvement of goodness of fit for the data in comparison to the one way ANOVA (.068) and Model $1(.061) .{ }^{17}$ 
Table 1: Effect of Contextual Factors on Political Trust across Chinese Provinces, 2001-2011

\begin{tabular}{|c|c|c|c|c|c|c|}
\hline \multirow{2}{*}{ Individual-Level } & \multicolumn{2}{|c|}{ Model 1} & \multicolumn{2}{|c|}{ Model 2} & \multicolumn{2}{|c|}{ Model 3} \\
\hline & & & & & & \\
\hline Social Trust & $.09 * *$ & $(.02)$ & $.09 * *$ & $(.02)$ & $.09 * *$ & $(.02)$ \\
\hline Economic Satisfaction & $.02^{* *}$ & $(.00)$ & $.02^{* *}$ & $(.00)$ & $.02^{* *}$ & $(.00)$ \\
\hline Politics Salient & $.12^{* *}$ & $(.02)$ & $.12^{* *}$ & $(.02)$ & $.12^{* *}$ & $(.02)$ \\
\hline Respect for Authority & $.05^{* *}$ & $(.01)$ & $.05^{* *}$ & $(.01)$ & $.05^{* *}$ & $(.01)$ \\
\hline National Pride & $.13^{* *}$ & $(.01)$ & $.13^{* *}$ & $(.01)$ & $.13^{* *}$ & $(.01)$ \\
\hline Age & $.00^{* *}$ & $(.00)$ & $.00^{* *}$ & $(.00)$ & $.00^{* *}$ & $(.00)$ \\
\hline Education & $-.07 * *$ & $(.01)$ & $-.07 * *$ & $(.01)$ & $-.07 * *$ & $(.01)$ \\
\hline Income & -.00 & $(.02)$ & -.00 & $(.02)$ & $-.04 *$ & $(.02)$ \\
\hline Female & $.04^{* *}$ & $(.01)$ & $.04^{* *}$ & $(.01)$ & $.04 * *$ & $(.01)$ \\
\hline \multicolumn{7}{|l|}{ Province-Level } \\
\hline Average Income & & & $.006^{* *}$ & $(.001)$ & $.005^{* *}$ & $(.001)$ \\
\hline Economic Inequality & & & $-.09 * *$ & $(.04)$ & $-.09 * *$ & $(.04)$ \\
\hline Openness & & & $-4.1 * *$ & $(1.34)$ & $-4.1 * *$ & $(1.32)$ \\
\hline Income $x$ Average Income & & & & & $.001 * *$ & $(.00)$ \\
\hline Education Rate & & & $-.65^{*}$ & $(.35)$ & $-.66^{*}$ & $(.34)$ \\
\hline Media Density & & & $-.30 * *$ & $(.10)$ & $-.27 * *$ & $(.11)$ \\
\hline Constant & $1.45^{* *}$ & $(.05)$ & $1.88^{* *}$ & (.18) & $1.92^{* *}$ & (.18) \\
\hline \multicolumn{7}{|l|}{ Random Effects Parameter } \\
\hline Survey & .01 & (.003) & .01 & $(.003)$ & .01 & $(.003)$ \\
\hline Residual & .22 & $(.01)$ & .22 & $(.01)$ & .22 & $(.01)$ \\
\hline Intraclass Correlation & \multicolumn{2}{|c|}{.061} & \multicolumn{2}{|c|}{.047} & \multicolumn{2}{|c|}{.048} \\
\hline \multicolumn{7}{|l|}{ Observations } \\
\hline Province Survey Units & \multicolumn{2}{|c|}{57} & \multicolumn{2}{|c|}{57} & \multicolumn{2}{|c|}{57} \\
\hline Individuals & \multicolumn{2}{|c|}{4410} & \multicolumn{2}{|c|}{4410} & \multicolumn{2}{|c|}{4410} \\
\hline \multicolumn{7}{|c|}{$\begin{array}{l}*=\text { Coefficient is significant at the } 0.10 \text { level. } * *=\text { Coefficient is significant at the } 0.05 \text { level. } \\
{ }^{\dagger} \text { The intra-class correlation for the oneway ANOVA is } .068 . \\
\text { Note: Entries are maximum likelihood coefficients estimated using Stata } 14 \text {, with robust standard errors in parentheses. } \\
\text { Higher values on the following individual-level variables indicate: higher social trust, economic satisifaction, salience of politic } \\
\text { respect for authority, national pride, age, education and income levels, and female. } \\
\text { Higher values on the following province-level variables indicate: higher GDP per capita, urban/rural income gap, } \\
\text { percentage of foreign enterprise workers inworkforce, percentage of individuals with only a middle school education, } \\
\text { and ratio of newspapers to total population. }\end{array}$} \\
\hline
\end{tabular}

To provide some sense of the substantive impact that our key independent variables have on political trust, we plot all of their unconditional effects side-by-side in Figure 5 based on the Model 2 
estimates. Comparing the magnitude of effects between our key independent variables moving from their minimum to maximum values reveals that per capita income (panel A) and openness (panel C) have the largest substantive effects on political trust. Although statistically significant, the substantive effect of economic inequality is relatively weak compared to the other economic indicators suggesting that perhaps the concern over this issue is overstated in the near term. The relatively strong effect of openness in decreasing political trust indicates that factors shaping performance expectations exert more influence than some of the actual institutional performance.

Figure 5: Unconditional Effects of Province-level Economic Factors on Political Trust
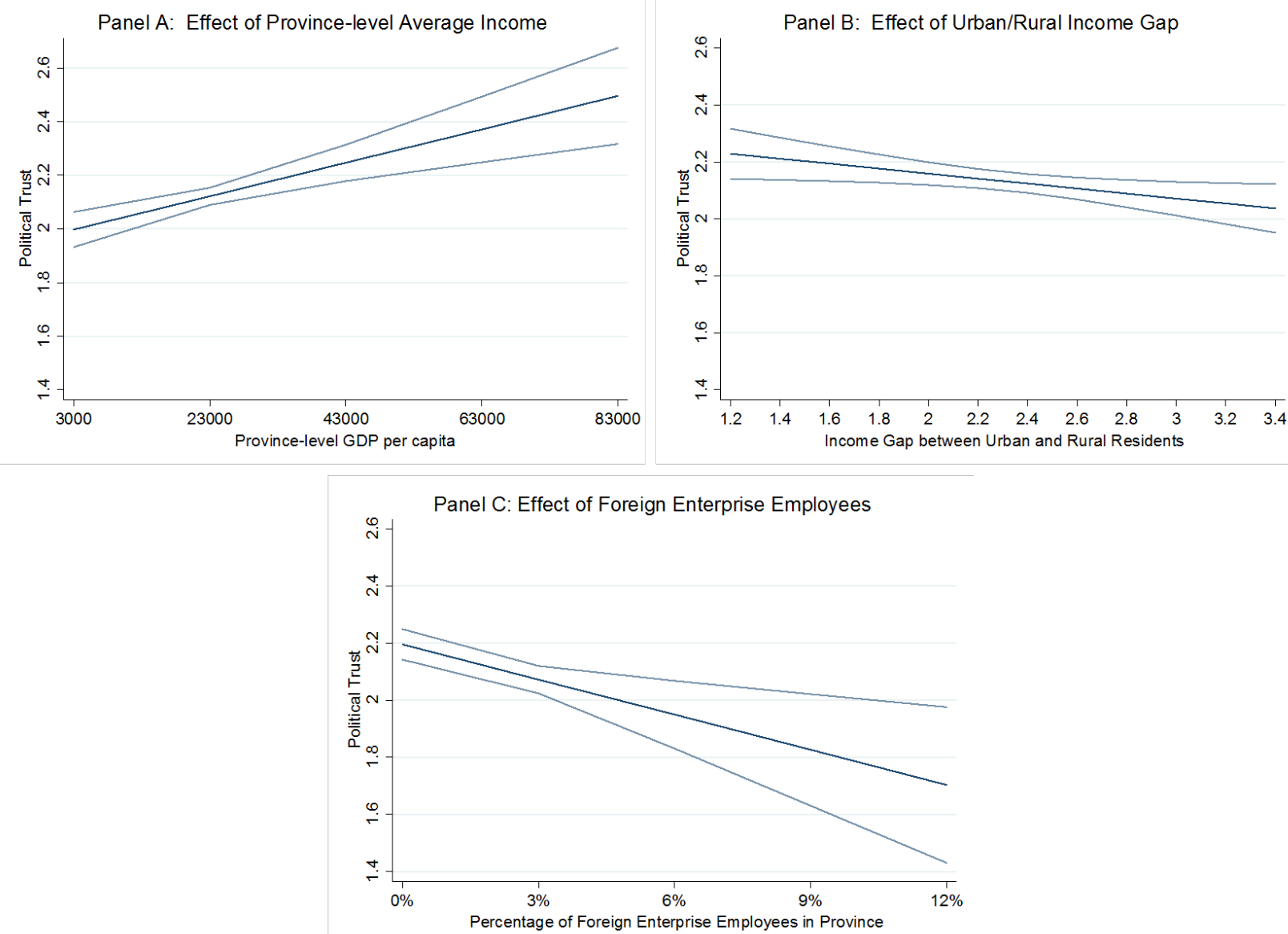
In terms of our province-level control variables, we find a negative and statistically significant effect of both province-level state-controlled education rates and media density on political trust. As postulated, high levels of media density can turn away citizens from trusting their governments. Our results indeed show that individuals residing in provinces with higher per capita newspaper subscriptions are less likely to trust government. This finding mirrors Chen and Shi's (2001) argument that exposure to propaganda makes the Chinese citizens distrust governments, it also echoes previous research linking individual media exposure to lower political trust in democracies (see Hetherington 2005). Macro-level education level turns out to have a negative and significant effect on political trust as well. This finding shows that not only one's own education level influences their trust in government but that the overall education levels of their more immediate environment also shapes their attitudes. In China, we observe that individuals living in a more educated province have lower overall levels of political trust.

In Model 3, we examine the conditional relationship between province-level income and individual income on political trust. In the previous models, we found no significant relationship between individual income and political trust but a positive and statistically significant relationship between province-level income and political trust. As we argue above $\left(\mathrm{H}_{1 \mathrm{~b}}\right)$, province-level wealth is likely to affect individuals on both extremes of the income scale in their political trust attitudes differently. Wealthier individuals are less likely to trust government institutions in poorer provinces but more trusting in wealthier provinces. In Model 3, the interaction term is positive and statistically significant, indicating that higher province-level wealth serves to raise political trust as individual income increases. The component terms are also statistically significant indicating differential effects across individual-income and province-level wealth scales.

In Figure 6, we plot how province-level wealth conditions the effect of income on political trust in China. While overall trust across all income groups in wealthier provinces is higher than in 
poor provinces, we also find significant differences between wealthy and poor provinces in which type of individuals along the income scale are more or less trusting of government. In wealthier provinces, high-income individuals are more trusting of government than lower income individuals while the opposite is true for individuals living in poor provinces. This finding adds an interesting wrinkle to our existing understanding of the relationship between income and political trust.

Previous cross-national research on trust consistently observed a largely negative relationship between income and trust as affluent individuals were less trusting of governments, particularly in advance industrial societies (see Inglehart 1997; Inglehart and Welzel 2005; Dalton 2004; Dalton and Shin 2006; Shin 2012). Here we see that, in China, this relationship is conditioned by the provincelevel economic conditions.

Figure 6: Conditional Effect of Province-level Wealth on Political Trust across Income Groups

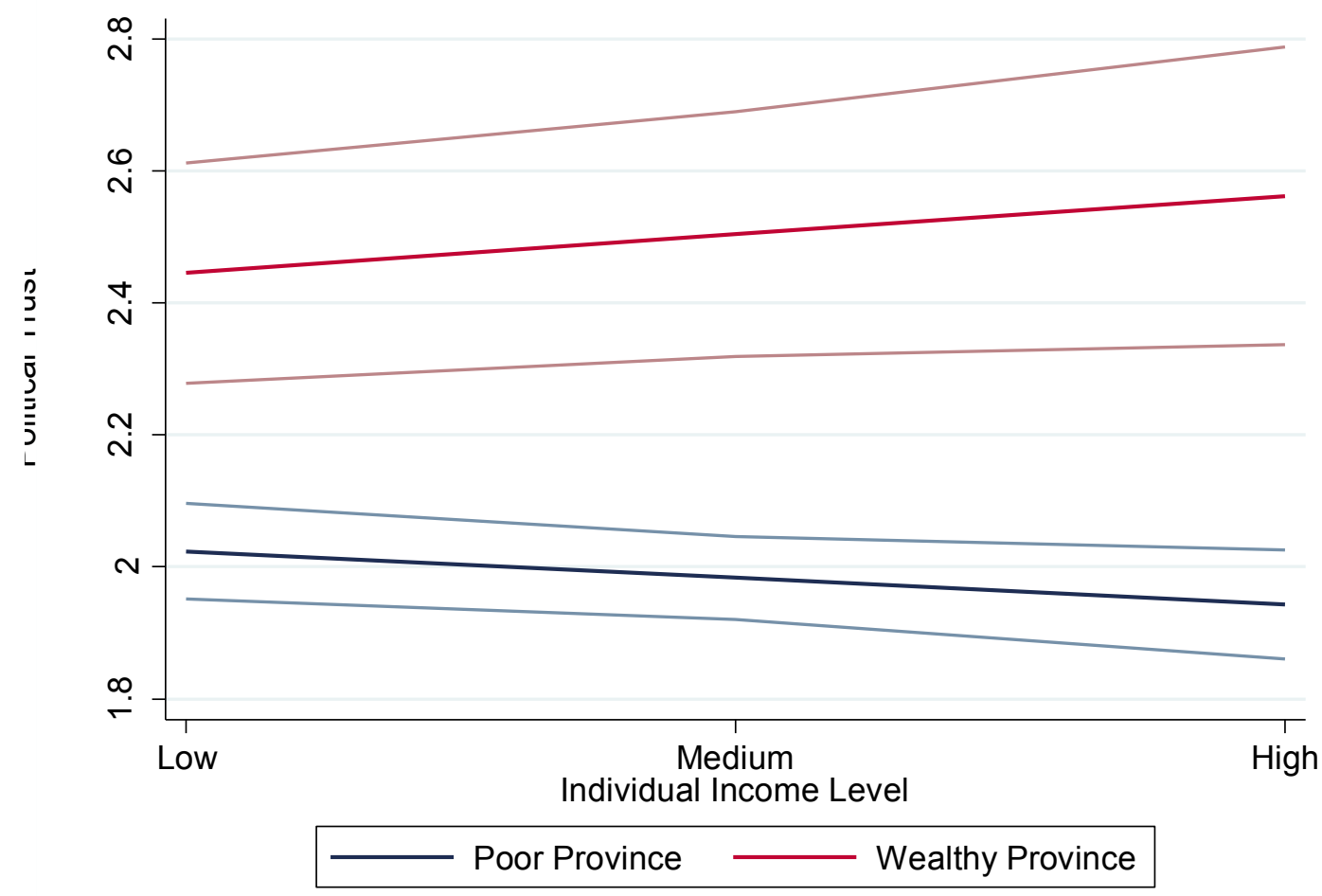


Overall, our analyses examining generalized political trust across Chinese provinces offer strong support for our hypotheses. These findings are consistent with our overall argument that, in general, Chinese citizens formulate political trust attitudes at the individual-level and respond to contextual factors in a manner similar to citizens in other regions and countries throughout the world. In terms of our contextual, province-level factors, we find very little difference in how Chinese citizens respond to economic inequality and wealth than in other regions throughout the world. ${ }^{18}$ What we do demonstrate, however, is that these factors are not evenly distributed throughout China, which may contribute variation in political trust levels across the country.

\section{Conclusion}

With the world's largest population, China's political future still hinges upon its citizens' support for the current government. As Welzel (2006) maintains, democratization research has long “downplayed the role of mass attitudes," for public aspiration for democracy is a strong predictor for regime change. To better understand China's political future as well as its current government's continued resilience, we focus here on political trust because of its importance as an indicator of regime legitimacy (Newton 2007). Numerous prior studies had documented the extreme high levels of political trust in the authoritarian Chinese government (see Li 2012; Wang 2007; Yang and Tang 2010; Wong et al. 2011). Departing from those national studies, we fully utilize provincial variation in various economic indicators to explore the effects of economic structural changes taking place in the past few decades on political trust in China.

By disaggregating World Value Surveys (WVS) data across Chinese provinces over a critical time period (2001-2012), our initial exploration has produced several important insights. First, economic performance is definitely an important explanation for political trust. Different from previous literature, we find that province-level economic performance and individual-level income 
combine to influence political trust. Wealthy and poor individuals respond to the economic performance in their home province quietly differently. In poor provinces, increases in personal wealth will reduce one's political trust and the opposite is true for wealthy provinces. We also observe that various social and political issues that China faces, i.e., rising income inequality, imbalance of regional developments, and increasing economic openness, all erode Chinese citizens' trust in their government. Third, when comparing the substantive effects of our province-level variables, we find that province-level economic performance, as measured by average income, and openness have the largest impact on trust, followed by rural-urban inequality.

These findings have important implications on China's political future. So far, China's immense economic growth has played an important role in boosting its citizens' trust in government, perhaps offsetting the negative effects of increasing openness and rising inequality on political trust. However, China has shown troubling signals of an economic slow-down. In 2014, China missed its official growth target for the first time in the past few decades. Unlike his predecessors who always prioritized economic growth, China's new President Xi Jinping calls for "less emphasis on growth and faster structural reform" (The Economist 2015). There is growing concern that China might face a major financial crisis in the near future because of the "imbalanced growth, government stimulus, overcapacity, an overwrought housing market, and a severely undercapitalized financial system” (Schuman 2015: 1; Kollewe and Monaghan 2015). Economic slowdown, particularly an economic crisis, will likely be coupled with rising social unrest and widening inequality resulting in a sharp decline in Chinese political trust.

Since the late 1970s, China has gradually and strategically opened up cities, towns and regions from the east coast to west inland. ${ }^{19}$ Opening up will inevitably expose China to alternative political thoughts and ideologies pertinent to democracy, government transparency, human rights and freedom of speech/association that will, consequently, alter Chinese citizens' expectations of 
their governmental institutions and decrease their political trust. Currently, the coastal provinces remain most economically open while the western inland provinces stay relatively closed to the global economy. Yet, once most Chinese regions gradually open up to the world, our results suggest that there might be a sharp decline in the overall trust in government.

Overall, our study provides critical insights into the nature of political trust in China, one of important sources of regime legitimacy for the current regime. It also offers important lessons for both the Chinese government and concerned citizens. While the Chinese government has been able to draw political support from the public by using its robust and growing economy (Shi 2001), the sharp gains in economic development may itself alter citizens' expectations in government and increase both the quantity and breadth of policy demand on the political institutions (see Dalton 2004). Indeed, this pattern echoes those earlier cross-national studies that observed declines in political trust among advanced industrial societies (Inglehart 1997; Dalton 2004; Inglehart and Welzel 2005; Norris 2011).

Additionally, the Chinese government should be aware of the limitations of censorship and propaganda in cultivating citizens' political trust. Our results show that both the media and education system runs counter its designed purpose of promoting governing legitimacy in China. Citizens exposed to an environment with higher levels of education rates and media density are less likely to trust their governments. Therefore, in order to strengthen citizens' confidence in the government, China must begin to tackle the inequality issue and adopt deeper political reforms. If left unaddressed, these two issues may cause their own citizens to challenge its governing legitimacy.

Undoubtedly, public opinion research in China is relatively underdeveloped compared to North America and Europe so there is still much work to be done in the future. Our study sets to examine the effects of various structural changes on political attitudes in China. This research endeavor is especially meaningful considering the unimaginable degree of changes experienced by 
the Chinese people in their economic, social and political lives. Of course, this study is not without its limitations. Compared to an experimental or true longitudinal panel design, we are mindful that an observational study like ours cannot offer the same level of causal evidence.

Yet, our findings may also have some implications for survey studies in China. We think that the reported high levels of trust at the national level might be overstated. For example, in all waves of the WVS, 10 Chinese provinces were excluded ${ }^{20}$, and perhaps not coincidentally, all 10 of these provinces have high economic inequality levels and six of these 10 excluded provinces are also relatively underdeveloped. ${ }^{21}$ Based on our findings, we reasonably speculate that the inclusion of these provinces in the WVS could possibly have resulted in lower national levels of political trust in China than currently reported. Given these external validity concerns, we caution researchers using these surveys, especially in cross-national studies, from drawing too strong of conclusions from the overall national averages. 


\section{ENDNOTES}

${ }^{1}$ One concern of studying political attitudes, such as political trust, in China is the possibility that respondents are afraid to be critical of the political system for fear of reprisal or repression. However, Wang (2007) suggests that this challenge may be overstated with respect to China (also see Chen and Shi 2001). He observed that Chinese respondents were more than willing to express criticism of their governments. Furthermore, as King et al. (2013) show, censorship in China does not typically silence criticism of the government and its institutions but is focused on inhibiting mobilization of collective actions.

2 A similar pattern of declining trust over time among advance industrial societies has been observed repeatedly in cross-national studies (see Inglehart 1997; Inglehart and Welzel 2005; Norris 1999, 2011; Dalton 2004; Dalton and Welzel 2014; Zmerli and Van der Meer 2016).

${ }^{3}$ Newton (2007: 344) argues, overall political trust comes "close to the concept of legitimation, which has more profound importance for the system of government than trust in particular political leaders or the government of the day." Trusting individuals can strengthen regime norms and contribute to political stability (Newton 2007; Hutchison and Johnson 2011).

${ }^{4}$ Space considerations limit our ability to offer an extended discussion of the 'Asian Values' hypothesis, but several studies provide a detailed overview of this debate (see Dalton and Shin 2006; Welzel 2011; Shin 2012). ${ }^{5}$ As of today, it is estimated that West China fell behind economically from the East Coast by at least 20 years. For instance, the three eastern coastal provinces Jiangsu, Zhejiang and Guangdong respectively enjoyed a per capita income of 52,840 RMB, 51,711 RMB and 44,736 RMB in 2011. Yet, the per capita income for the four west inland provinces Guizhou, Yunnan, Gansu and Tibet in the same year was only 13,119 RMB, 15,752 RMB, 16,113 RMB, and 17,319 RMB.

${ }^{6}$ We speculate that the elimination of agricultural taxes in 2007 played an important role in stabilizing the urban-rural inequality after 2008.

7 The "Democracy Wall" and the "1989 Tiananmen Movement" were perhaps the most notable events. 8 Here we use the percentage of employees working in foreign enterprises as a proxy measure of openness. ${ }^{9}$ The World Values Survey is a global survey project conducted over dozens of countries throughout the world and over time. These data are publicly available and accessed at www.worldvaluessurvey.org. All the province-level data were collected from the Chinese Statistical Yearbooks (2001-2013) published by the China Statistics Bureau, and carefully compiled by the authors.

10 According the codebook descriptions of the sampling procedures, several 'remote provinces' were excluded for largely budgetary reasons. Across the three waves of WVS, the following provinces were omitted from our sample due to missing surveys in one or more of the waves. These excluded provinces include Xinjiang, Tibet, Qinghai, Ningxia, Gansu, Yunnan, Sichuan, Chongqing, Inner Mongolia, and Jilin.

${ }^{11}$ In the 2001 survey, the multistage stratified sample was based on provinces as the initial stratification unit with counties and county-level cities serving as the PSUs. As a result, the overall country sample was smaller in 2001, with 25 family households as the basic sampling unit for each province. The adjustments to the sampling framework for the 2007 and 2012 waves were intended to reduce the urban bias of the 2001 wave and reduce the disparity in sampling between urban and rural areas with additional stratification. In 2007 and 2012, seven general regions served as the initial stratification units with counties and county-level cities serving as the PSUs. Overall, the 2007 and 2012 waves are considered less urban-biased and more nationally representative. For more information about the sampling procedures, please refer to the codebooks available at www.worldvaluessurvey.org.

12 To alleviate any concerns regarding multicollinearity between our economic variables, we conducted several diagnostic analyses and found no evidence of multicollinearity between our variables. The analyses revealed a mean VIF score of 1.91, which is well below the common threshold of 10. Additionally, the tolerance scores and condition numbers for each variable indicate that we do not suffer from multicollinearity problems with our economic variables.

13 Please refer to our online appendix for further details on the multiple imputation procedures for missing values among our independent variables. However, because our imputation model matches our analysis 
model, we use the unimputed values for our dependent variable to avoid adding more error to the analyses below (see Von Hippel 2007).

${ }^{14}$ In the models below, we use a random intercept specification for Models 1 and 2 Because we include a cross-level interaction term in Model 3, we use a random coefficient specification that allows the slope of the individual-level income variable to vary.

${ }^{15}$ A comparison of the ICC coefficients reveals that Model 1 represents a $10 \%$ improvement over the oneway ANOVA in terms of overall model fit.

16 An anonymous reviewer suggested that the effect of economic development on political trust may be nonlinear, similar to previous findings at the country-level. To test this, we conducted several robustness checks of Model 2 in which we included squared and cubed terms of our average income variable. We find no evidence that this type of nonlinear relationship exists between province-level economic development and political trust within our data. Although we find no evidence of this effect in our models, we believe this difference in effect between county and province-level economic development is noteworthy.

${ }_{17}$ A comparison of the ICC coefficients reveals that Model 2 represents a 31\% improvement over the oneway ANOVA and a 23\% improvement over Model 1 in terms of overall model fit.

18 To determine whether our study suffers from omitted variable bias stemming from factors other than economic development and performance that reflect higher quality of governance, we conduct several robustness checks to assess whether our results hold after controlling for other measures of government quality. The primary challenge is the lack of indicators disaggregated to the province-level in China.

Therefore, we use several indicators of China's overall quality of governance at the national level that change over time across our three survey waves: relative political capacity (Kugler et al. 2013), ICRG quality of government index (Dahlberg et al. 2016), and the World Bank government effectiveness index (Dahlberg et al. 2016). We find no substantive changes to our key independent variables from the results reported in Model 2. The only notable difference is that the statistical significance level of our province average income variable drops from .05 to the .10 in the models controlling for relative political capacity $(p=0.053)$ and the World Bank government effectives index $(\mathrm{p}=0.072)$. We present these findings in Table A3 of our online appendix.

${ }^{19}$ China gradually opened up cities and regions through four important steps. First, it opened up the five coastal cities (Shenzhen, Zhuhai, Shantou, Xiamen and Haikou) as its "Special Economic Zones" in the early 1980s. The second step expanded the open-up policy to 14 cities on the east coast. The third step opened up three coastal economic belts: the Yangtze River Delta, Pearl River Delta and the Southern Fujian Delta region. The fourth step opened up dozens of inland cities including those along the Yangtze River, provincial capitals, as well as northern and western bordering cities and towns. Currently, cities and towns that are open to foreign investment can be found in all Chinese provinces.

${ }^{20}$ Please refer to footnote 10 for a list of the excluded provinces in our analyses.

21 The following six provinces are underdeveloped and also excluded from WVS: Tibet, Qinghai, Gansu, Ningxia, Inner Mongolia, and Jilin. 


\section{REFERENCES}

Almond G and Verba S (1963) The Civic Culture. Princeton, NJ: Princeton University Press.

Anderson CJ and Singer MM (2008) The sensitive left and the impervious right: Multilevel models and the politics of inequality, ideology, and legitimacy in Europe. Comparative Political Studies 41(4/5):564-599.

Catterberg G and Moreno A (2005) The individual bases of political trust: Trends in new and established democracies. International Journal of Public Opinion Research 18(1):31-48.

Chen J, Zhong Y and Hillard JW (1997) The level and sources of popular support for China's current political regime. Communist and Post-Communist Studies 30(1):45-64.

Chen X and Shi T (2001) Media effects on political confidence and trust in the People's Republic of China in the post-Tiananmen period. East Asia: An International Quarterly 19(3):84-118.

Dahlberg, S, Holmberg S, Rothstein B, Khomenko A and Svensson R (2016) The Quality of Government Basic Dataset, version Jan16. University of Gothenburg: The Quality of Government Institute. Available at http:/ /www.qog.pol.gu.se> (Accessed October 3, 2016).

Dalton RJ (2004) Democratic Challenges, Democratic Choices. New York: Oxford University Press.

Dalton RJ and Ong NT (2006) Authority orientations and democratic attitudes: A test of the "Asian Values' Hypothesis." In: Dalton RJ and Shin DC (eds) Citizens, Democracy and Markets around the Pacific Rim. New York: Oxford University Press, 97-112.

Dalton RJ and Shin DC (eds) (2006) Citizens, Democracy and Markets around the Pacific Rim. New York: Oxford University Press.

Dalton RJ and Welzel C (eds) (2014) The Civic Culture Transformed. Cambridge: Cambridge University Press.

Espinal R, Hartlyn J and Kelly JM (2006) Performance still matters: Explaining trust in government in the Dominican Republic. Comparative Political Studies 39(2): 200-223.

Geddes B and Zaller J (1989) Sources of support for authoritarian regimes. American Journal of Political Science 33(2):319-347.

Gurr TR (1970) Why Men Rebel. Princeton, NJ: Princeton University Press.

Gustafsson BA, Li S and Sicular T (2008) Inequality and Public Policy in China. Cambridge: Cambridge University Press.

Hetherington MJ (2005) Why Trust Matters. Princeton, NJ: Princeton University Press.

Hutchison ML (2011) Territorial threat and the decline of political trust in Africa: A multilevel analysis. Polity 43(4):432-461.

Hutchison ML and Johnson K (2011) Capacity to trust? Institutional capacity, conflict, and political trust in Africa, 2000-2005. Journal of Peace Research 48(6):737-752.

Inglehart R (1997) Modernization and Postmodernization. Princeton: Princeton University Press.

Inglehart R and Welzel C (2005) Modernization, Cultural Change, and Democracy. Cambridge: Cambridge University Press. 
Jennings MK (1998) Political trust and the roots of devolution. In: Braithwaite V and Levi M (eds) Trust in Governance. New Yok: Russell Sage.

Johnson K and Hutchison ML (2012) Hybridity, political order, and legitimacy: Examples from Nigeria. Journal of Peacebuilding and Development 7(2):153-168.

Kanbur R and Zhang X (1999) Which regional inequality? The evolution of rural-urban and inlandcoastal inequality in China from 1983 to 1995. Journal of Comparative Economics 27(4):686-701.

Kennedy JJ (2009) Maintaining popular support for the Chinese communist party: The influence of education and the state-controlled media. Political Studies 47(3):517-536.

Key VO (1961) Public Opinion and American Democracy. New York: Knopf.

Kim J (2010) Income inequality in China. The Journal of East Asian Affairs 24(2):29-50.

King G, Pan J and Roberts ME (2013) How censorship in China allows government criticism but silences collective expression. American Political Science Review 107(2):326-343.

Knack S and Keefer P (1997) Does social capital have an economic payoff? A cross-country investigation. Quarterly Journal of Economics 65(4):1251-1288.

Kollewe J and Monaghan A (2015) Analysts fear China financial crisis as deflation looms. The Guardian, 9 January, 2015.

Kugler, J, Abdollahian M, Johnson K, Arbetman-Rabinowitz M, Kang K, and Fistanglu A (2013) Relative Political Capacity Data Update. Data file. Institute for Quantitative Social Science at Harvard University. Available at: https://dataverse.harvard.edu/dataverse/rpc (Accessed October 1, 2016).

Kumlin S (2011) Claiming blame and giving credit? Unintended effects of how government and opposition frame the Europeanization of welfare. European Union Politics 12(4):575-595.

Li L (2012) The magnitude and resilience of trust in the center: Evidence from interviews with petitioners in Beijing and a local survey in rural China. Modern China 39(1):3-36.

Mishler W and Rose R (2001) What are the origins of political trust? Testing institutional and cultural theories in post-communist societies. Comparative Political Studies 34(1):30-62.

Newton K (2001) Trust, social capital, civil society, and democracy. International Political Science Review 22(2):201-214.

Newton K (2007) Social and political trust. In: Dalton RJ and Klingermann HD (eds) Oxford Handbook of Political Behavior. New York: Oxford University Press.

Newton K and Zmerli S (2011) Three forms of trust and their association. European Political Science Review 3(2):169-200.

Norris P (ed) (1999) Critical Citizens. New York: Oxford University Press.

Norris P (2000) The Virtuous Circle. Cambridge: Cambridge University Press.

Norris P (2011) Democratic Deficit. Cambridge: Cambridge University Press.

Rothstein B (2011) The Quality of Government. Chicago: University of Chicago Press.

Schuman M (2015) China may be heading for a Japanese-style economic crisis. Time, 12 September, 2014. 
Shi T (2001) Cultural values and political trust: A comparison of the People's Republic of China and Taiwan. Comparative Politics 33(4):401-419.

Shin DC (2012) Confucianism and Democratization in East Asia. Cambridge: Cambridge University Press.

Snijders TAB and Bosker RJ (2012) Multilevel Analysis, $2^{\text {nd }}$ edition. London: Sage Publishers.

The Economist (2015) Why China's economy is slowing. The Economist, 11 March, 2015.

Uslaner EM (2002) The Moral Foundations of Trust. Cambridge: Cambridge University Press.

Uslaner EM (2011) Corruption, the inequality trap, and trust in government. In: Hooghe M and Zmerli S (eds) Political Trust. Colchester, UK: ECPR Press.

Von Hippel PT (2007) Regression with missing Ys: An improved strategy for analyzing multiply imputed data. Sociological Methodology 37(1):83-117.

Warren ME (ed) (1999) Democracy and Trust. Cambridge: Cambridge University Press.

Wang Z (2005) Before the emergence of critical citizens: Economic development and political trust in China. International Review of Sociology 15(1):155-171.

Wang Z (2007) Public support for democracy in China. Journal of Contemporary China 16(53):561-579.

Wedeman A (2005) Anticorruption campaigns and the intensification of corruption in China. Journal of Contemporary China 14(42):93-116.

Welzel C (2006) Democratization as an emancipative process: The neglected role of mass motivations. European Journal of Political Research 45(6):871-896.

Welzel C (2011) “The Asian values thesis revisited: Evidence from the World Values Survey." Japanese Journal of Political Science 13(1):1-13.

Welzel C, Inglehart R and Klingemann HD (2003) The theory of human development: A crosscultural analysis." European Journal of Political Research 42(3):341-380.

Wong TK, Wan P and Hsiao HHM (2011) Bases of political trust in six Asian societies: Institutional and cultural explanations compared. International Political Science Review 32(3):263-281.

Xue J (2013) Income inequality in China. Paper presented at the 2013 World Economics Association 2013 conference on "Inequalities in Asia”, 27 May-12 July, 2013.

Yang DT (1999) Urban-biased policies and rising income inequality in China. The American Economic Review 89(2):306-310.

Yang Q and Tang W (2010) Exploring the sources of institutional trust in China: Culture, mobilization, or performance? Asian Politics and Policy 2(3):415-336.

Zmerli S and Newton K (2008) Social trust and attitudes towards democracy. Public Opinion Quarterly 72(4):706-724.

Zmerli S and Van der Meer T (eds) (2016) Handbook of Political Trust. London: Edward Elgar Publishing. 